Original Research Article

\title{
An observational study to monitor cutaneous adverse drug reaction profile in Dermatology Department of tertiary care teaching hospital
}

\author{
Janaki R. Torvi, S. G. S. Rajesh Reddy V.*
}

Department of Pharmacology, Karnataka Institute of Medical Sciences, Hubli, Karnataka, India

Received: 09 February 2019 Accepted: 15 February 2019

\section{*Correspondence to:}

Dr. S. G. S. Rajesh Reddy V., Email: rajesh.vsgs@gmail.com

Copyright: (C) the author(s), publisher and licensee Medip Academy. This is an openaccess article distributed under the terms of the Creative Commons Attribution NonCommercial License, which permits unrestricted noncommercial use, distribution, and reproduction in any medium, provided the original work is properly cited.

\begin{abstract}
Background: Incidence of cutaneous adverse drug reactions (CADRs) in developed countries is 1 to $3 \%$ and in developing countries, it is much higher i.e. 2 to $6 \%$. 1 in 1000 hospitalized patients will develop severe cutaneous adverse reaction. Maculopapular rash represents majority of cutaneous drug reaction followed by urticaria. Most frequently elicited CADRs are associated with antimicrobials and NSAIDs. This study was designed to monitor Cutaneous adverse drug reaction profile of tertiary care teaching hospital.

Methods: This is a prospective observational study of 6 months' duration to monitor cutaneous adverse drug reactions in dermatology department of tertiary care teaching hospital. CADRs were analysed with respect to demographic details, suspected drugs and type of reaction. Causality assessment is by Naranjo algorithm. Data is represented in tables and graphs. Data is analyzed in Microsoft excel 2007.

Results: Total 57 cases of cutaneous adverse drug reactions were reported. Among them, $57.9 \%$ were in males and $42.1 \%$ were in females. Majority of CADRs were due to antiretroviral drugs (38.5\%) followed by antibacterial (28\%) and antiepileptics (14\%). Maculopapular rash is most common CADR (35\%). Causality of $74 \%$ CADRs were probable according to Naranjo algorithm.

Conclusions: CADRs are more commonly associated with antiretroviral therapy (ART), antibacterial drugs and antiepileptic drugs. In case of ART, antiepileptic drug and drugs used in chronic illness compliance plays a major role in the success of therapy. Adverse drug reactions lead to problem of non compliance and failure of therapy. Cutaneous adverse reactions like FDE heal with hyper pigmentation leads to cosmetic problem. Stevens Johnson syndrome (SJS) is life threatening that requires prompt withdrawal of drug and intensive medical management. Many drugs are available without prescription in India leading to problem of misdiagnosis of CADRs. So, data obtained from this study helps in proper diagnosis and treatment of CADRs.
\end{abstract}

Keywords: CADR, Cutaneous adverse drug reaction, Maculopapular, SJS

\section{INTRODUCTION}

Incidence of cutaneous adverse drug reactions (CADRs) in developed countries is 1 to $3 \% .^{1}$ In developing countries it is much higher 2 to $6 \% .1$ in 1000 hospitalized patients will develop severe cutaneous adverse reaction. A study found drug induced adverse skin reactions to be $2.6 \%$ at dermatology outpatient setting. ${ }^{2}$ Different forms of skin reaction are 1) morbiliform 2) fixed drug eruptions 3 ) phototoxic 4) urticaria 5) exfoliative dermatitis 6) Stevens Johnson syndrome (SJS) 7) Toxic epidermal necrolysis.

Maculopapular rash represents majority of cutaneous drug reaction $(95 \%)$ followed by urticaria. ${ }^{3}$ In a study by Thappa et al most common eruptions were fixed drug eruptions $(31.1 \%)$. Although virtually any drug is capable of eliciting an adverse reaction. Most frequently elicited are antimicrobials and NSAIDs. ${ }^{4}$ 
The relative risk of Stevens Johnson syndrome and toxic epidermal necrolysis perhaps most important severe cutaneous reactions has been quantified in an international case control study and case series sulfonamide antibiotics, amine antiepileptic (phenytoin and carbamazepine), lamotrigine, oxicam NSAIDs are associated with highest risk. ${ }^{5}$ This study was designed to monitor Cutaneous adverse drug reaction profile of tertiary care teaching hospital.

The objectives of current research work are to study patient characteristics presenting with ADR and to study common drugs implicated in CADRs. Also, to study different types of cutaneous adverse drug reactions.

\section{METHODS}

A prospective observational study. All outpatients and inpatients of Dermatology Department KIMS, Hubli. This study was conducted from August 2015 To January 2016 (6months). This study was conducted at KIMS Hospital, Hubli, Karnataka, India.

\section{Method of collection of data}

After obtaining approval and clearance from Institution Ethics Committee, 57 cutaneous ADRs reported from dermatology department KIMS, Hubli over a period of 6 months were included in study. Written and informed consent was obtained from all study subjects. To collect data ADR reporting forms were distributed in Dermatology department and requested them to report suspected ADRs to department of pharmacology. We also actively monitored ADRs by attending Dermatology OPD and inpatient rounds along with dermatologists twice in a week. The demographic data of patients reporting CADRs and brief description of event, suspected drug(s) were collected during the study period.

The pattern of cutaneous CADRs reported were analyzed. The causality of reactions was analyzed by Naranjo causality scale. Severity of CADRs was assessed using modified Hatwig and Siegel scale. Confidentiality of patients was maintained throughout and after study.

\section{Statistical analysis}

Data was analyzed using frequency and percentages. Data was described in the form of tables and graphs. Data was entered in Microsoft excel 2007.

\section{RESULTS}

A total of 57 CADRs were reported over 6 months. Of these, $57.9 \%$ were in males and $42.1 \%$ were in females (Figure 1).

Maximum number of CADRs reported in young adults of age group 18-39 yrs (40\%) followed by people with age groups 40-59yrs (29.8\%), 59yrs (17.5\%) and <18yrs (12.2\%) (Table 1).

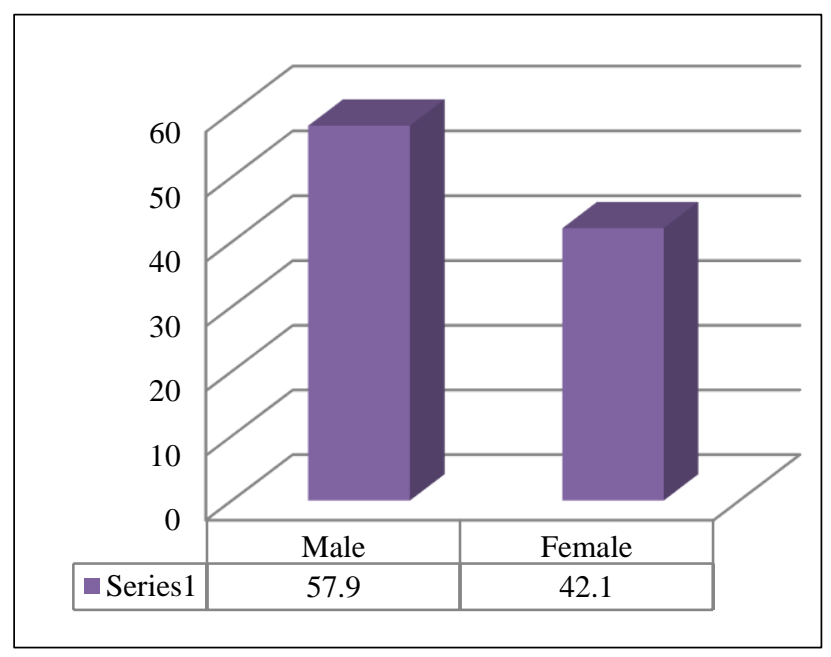

Figure 1: Sex wise distribution of CADRs.

Table 1: Age wise distribution of CADRs.

\begin{tabular}{|lll|}
\hline AGE & No of CADRs & Percentage \\
\hline$<18$ yrs & 07 & 12.2 \\
\hline $18-39 y r s$ & 23 & 40 \\
\hline $40-59 y r s$ & 17 & 29.8 \\
\hline$>59 y r s$ & 10 & 17.5 \\
\hline
\end{tabular}

Among the suspected drugs causing ADRs, antiretroviral agents accounted for $38.5 \%$ of the total CADRs followed by antibacterial drugs (28\%), antiepileptics (14\%), NSAIDS (5.2\%), anticancer drugs (5.2\%), antihypertensives (3.5\%), local anesthetics (1.7\%), antidiabetic (1.7\%) and antipsychotic drugs (Table 2).

Table 2: CADRs in various drug classes.

\begin{tabular}{|llc|}
\hline Drugs & No of CADRs (57) & Percentage \\
\hline Antiretroviral & 22 & 38.5 \\
\hline Antibacterial & 16 & 28 \\
\hline Antiepileptic & 08 & 14 \\
\hline NSAIDS & 03 & 5.2 \\
\hline Anticancer & 03 & 5.2 \\
\hline Antihypertensive & 02 & 3.5 \\
\hline Local anesthetic & 01 & 1.7 \\
\hline Antidiabetic & 01 & 1.7 \\
\hline Antipsychotic & 01 & 1.7 \\
\hline
\end{tabular}

Among CADRs maculopapular rash $(35 \%)$ is most common followed by Fixed drug eruptions (14\%), urticaria $(10 \%)$, exfoliative rash $(9 \%)$, erythematous plaques (9\%), Stevens Johnson Syndrome (7\%), type 2 lepra reaction $(7 \%)$, alopecia $(5 \%)$, erythema multiforme (1\%) and lichenoid drug eruption (1\%) (Figure 2).

Assessment of ADRs using Naranjo's causality assessment scale showed that $74 \%$ of CADRs were 
probable, $26 \%$ were classified as possible and none of CADRs were definte and doubtful (Table 3).

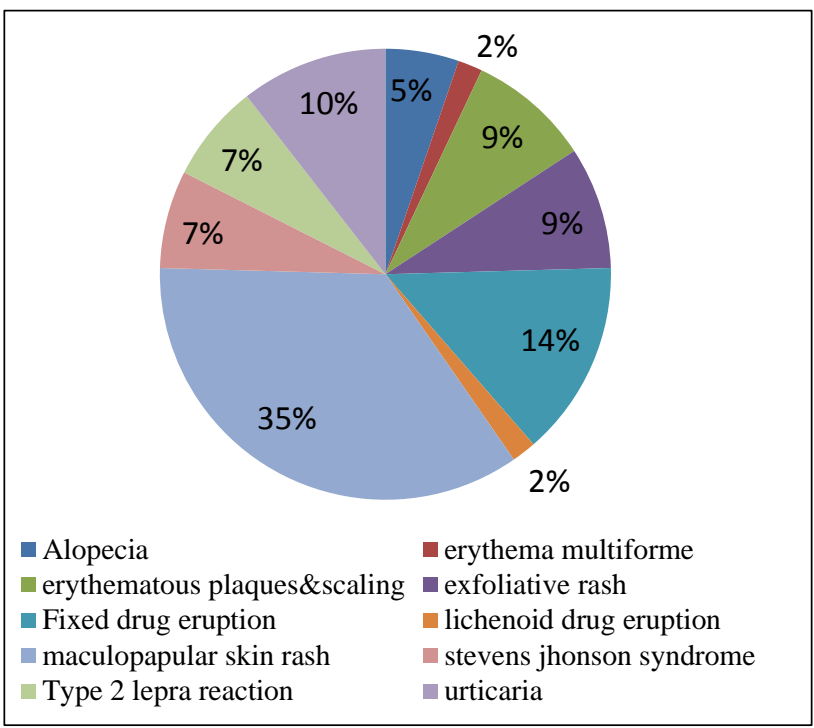

Figure 2: Types of CADRs.

Table 3: Causality assessment using Naranjo algorithm.

\begin{tabular}{|lll|}
\hline Causality & No of CADRs & Percentage \\
\hline Definite & 00 & 00 \\
\hline Probable & 42 & 74 \\
\hline Possible & 15 & 26 \\
\hline Doubtful & 00 & 00 \\
\hline
\end{tabular}

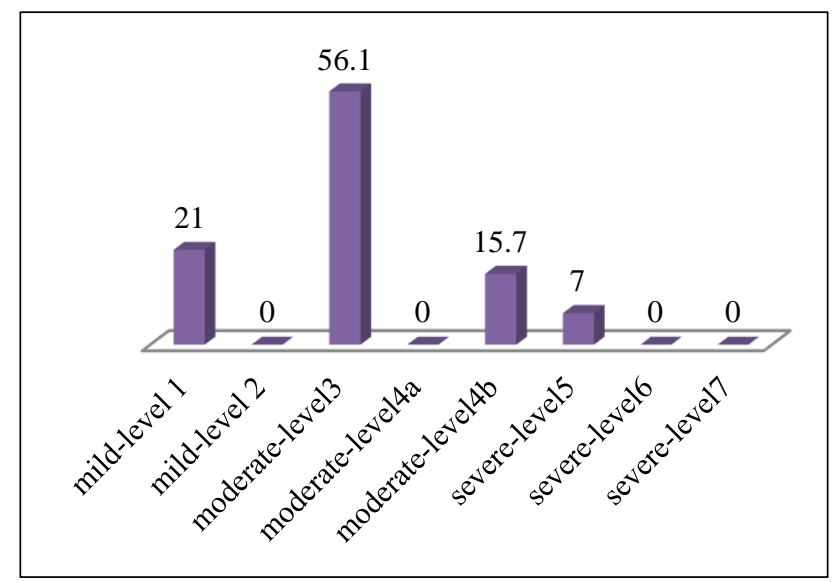

Figure 3: Severity of CADRs assessed by modified Hatwig and Siegel scale.

According to modified Hatwig and Siegel scale $21 \%$ of ADRs was mild level 1. These ADRs are self-limiting and don't require drug discontinuation. But these ADRs should also be followed up for increase in severity. $56.1 \%$ of ADRs were moderate level 3 these ADRs require medical treatment and need change or withdrawal of drug. $15.7 \%$ of ADRs were moderate level $4 \mathrm{~b}$ these were reasons for hospital admission. $7 \%$ of ADRs were severe level 5 requiring intensive medical treatment.

\section{DISCUSSION}

In our study 57 Cases of CADRs were reported. Out of which $33(57.9 \%)$ were males and $24(42.1 \%)$ were females. So, percentage of CADRs in males was higher than in females.

Our study result was similar to studies done at Chandigarh where male predominance was seen. ${ }^{6,7}$ This result differs from studies done in South India which reports almost equal incidence $(0.87: 1){ }^{8}$ As all these studies were institution based, this difference in demographic profile can be accounted by the difference in the demography of the patients attending the clinic.

In our study ADRs most commonly occurred with antiretroviral drugs (38.5\%), antibacterial drugs (28\%) and antiepileptic drugs (14\%). In our study most common skin reaction was maculopapular rash $(35 \%)$ followed by fixed drug eruption $(14 \%)$ and urticaria $(10 \%)$.

One case of erythema multiforme is seen with phenytoin. One case of lichenoid drug eruption is seen with carbamazepine. Cases of fixed drug eruptions with doxycycline, ciprofloxacin and diclofenac. Stevens Johnson Syndrome seen with HAART in our study.

A study conducted in Manipal reported that antimicrobials $(30 \%)$ were most commonly implicated in CADRs. ${ }^{9}$ Another study reported that maculopapular rash (50\%) and urticaria $(21.5 \%)$ were most common CADRs. ${ }^{10}$ Another study in inpatients also reported that maculopapular rash is most common CADR in hospitalized patients and antimicrobials were most common drugs. ${ }^{11}$

\section{CONCLUSION}

CADRs are more commonly associated with antiretroviral therapy (ART), antibacterial drugs and antiepileptic drugs. In case of ART, antiepileptic drug and drugs used in chronic illness compliance plays a major role in success of therapy. Adverse drug reactions lead to problem of non compliance and failure of therapy. Cutaneous adverse reactions like FDE heal with hyper pigmentation leads to cosmetic problem. Stevens Johnson syndrome (SJS) is life threatening requires prompt withdrawal of drug and intensive medical management. Many drugs are available without prescription in India leading to problem of misdiagnosis of CADRs. So, data obtained from this study helps in proper diagnosis and treatment of CADRs.

Funding: No funding sources

Conflict of interest: None declared

Ethical approval: The study was approved by the Institutional Ethics Committee

\section{REFERENCES}

1. Bigby M. Rates of cutaneous reactions to drug. Arch Dermatol. 2000;137:765-70. 
2. Chatterjee S, Ghosh AP, Barbhuiya J, Dey SK Adverse cutaneous drug reactions: A one year survey at a dermatology outpatient clinic of a tertiary care hospital. Indian J Pharmacol. 2006;38:429-31.

3. Alanko K, Stubb S, Kauppien K. Cutaneous drug reactions: Clinical types and causative agents a five year survey of inpatients (1981-1985). Acta Derm Venerol. 1989;69:223-26.

4. Chatterjee S, Ghosh AP, Barbhuiya, Dey SK. Adverse drug reactions: A one year survey at a dermatology outpatient clinic of a tertiary care hospital. Ind $\mathbf{J}$ Pharmacol. 2006;38:429-31.

5. Chosidow OM, Stern RS, Wintroub BU. Cutaneous drug reaction. In: Kasper DL, Braunwald, editor. Harrisons principles of internal medicine. 16thed. New York: Mc Graw Hill; 2005:318.

6. Sharma VK, Sethuraman G, Kumar B. Cutaneous adverse drug reactions: Clinical pattern and causative agents-a 6-year series from Chandigarh, India. J Postgrad Med. 2001;47:95-9.

7. Sharma VK, Dhar S. Clinical pattern of cutaneous drug eruption among children and adolescents in north India. Pediatr Dermatol. 1995;12:178-83.
8. Pudukadan D, Thappa DM. Adverse cutaneous drug reactions: Clinical pattern and causative agents in a tertiary care centre in South India. Ind J Dermatol Venereol Leprol. 2004;70:20-4.

9. Ghosh S, Leelavathi D, Padma GM. Study and evaluation of various cutaneous adverse drug reactions in Kasturba hospital, Manipal. Indian J Pharm Sci. March 2006;68:212.

10. Jhah R, Uppal R, Malhotra S, Bhargava VK. Cutaneous adverse reactions in inpatients in a tertiary care hospital. Indian J Dermatol Venerol Leprol. 1999;65:14-7.

11. Noel MV, Sushma M, Guido S. Cutaneous adverse reactions in inpatients in a tertiary care hospital. Indian J Pharmacol. 2004;36:292-5.

Cite this article as: Torvi JR, Reddy VR SGS. An observational study to monitor cutaneous adverse drug reaction profile in Dermatology Department of tertiary care teaching hospital. Int J Basic Clin Pharmacol 2019;8:442-5. 